\title{
Cultura tributaria e intención de formalización de los emprendedores bodegueros del Distrito de Morales - San Martín, 2021
}

Tax culture and intention to formalize the winery entrepreneurs of the Morales District - San Martín, 2021

Cultura fiscal e intenção de formalizar entre os empresários do vinho no Distrito de Morales - San Martín, 2021

\author{
Mariela Del Rocio Copia Romero \\ e-mail: dcopiaro6@ucvvirtual.edu.pe \\ Universidad Cesar Vallejo - Perú \\ https://orcid.org/0000-0003-4689-7047
}

Max Fredy Romero Tello e-mail: mfromeror@ucvvirtual.edu.pe

Universidad Cesar Vallejo - Perú https://orcid.org/0000-0002-7117-1881

\author{
Segundo Eloy Soto Abanto \\ e-mail:ssotoa@ucv.edu.pe \\ Universidad Cesar Vallejo - Perú \\ https://orcid.org/0000-0003-1004-5520
}

Avelino Sebastián Villafuerte de la Cruz e-mail: avillafuerted@ucvvirtual.edu.pe

Universidad Cesar Vallejo - Perú https://orcid.org/0000-0002-9447-8683

\begin{abstract}
RESUMEN
La presente investigación buscó encontrar si existe relación entre las variables cultura tributaria e intención de formalización de los emprendedores bodegueros del distrito de Morales - San Martín 2021, se consideró la investigación de tipo aplicada, se utilizó un enfoque cuantitativo de tipo no experimental transversal y de alcance correlacional. Se aplico la técnica la encuesta y el instrumento el cuestionario en las variables de estudio, en una muestra de 59 emprendedores bodegueros, tras la recopilación de los datos, se procedió a realizar la tabulación y el análisis descriptivo e inferencial, se encontró que la cultura tributaria se encuentra en nivel medio y la intención de formalización se encuentra en un nivel alto, realizando la prueba de Rho de Spearman obtenemos una significancia de 0.165 el cual indica que no hay relación entre las variables, se concluyó que no es necesario tener un alto índice de cultura tributaria para que el emprendedor tenga intención de formalizar, ya que hay emprendedores que tienen poca cultura tributaria y tienen la intención de formalizar a diferencia de otros emprendedores que tienen alto nivel de cultura tributaria y no tiene intención de formalizar por falta de confianza con el Estado, quiere decir que cada variable tiene direcciones independientes.
\end{abstract}

Palabras clave: Tributación, cultura tributaria, formalización, informalidad

\begin{abstract}
The present research sought to find if there is a relationship between the variables tax culture and intention to formalize of the winery entrepreneurs of the district of Morales - San Martin 2021, the research was considered applied type, a quantitative approach of non-experimental cross-sectional type and correlational scope was used. The survey technique and the questionnaire instrument were applied to the study variables, in a sample of 59 winery entrepreneurs, after the data collection, we proceeded to perform the tabulation and the descriptive and inferential analysis, it was found that the tax culture is at a medium level and the intention of formalization is at a high level, performing the Spearman's Rho test we obtained a significance of 0.165 which indicates that there is no relationship between the variables, it was concluded that it is not necessary to have a high index of tax culture for the entrepreneur to have the intention to formalize, since there are entrepreneurs who have a low tax culture and have the intention to formalize unlike other entrepreneurs who have a high level of tax culture and have no intention to formalize due to lack of confidence with the State, meaning that each variable has independent directions.
\end{abstract}


Keywords: Taxation, tax culture, formalization, informality.

\section{RESUMO}

A presente pesquisa procurou descobrir se existe uma relação entre as variáveis cultura fiscal e intenção de formalizar os empresários vitivinícolas do distrito de Morales - San Martin 2021, a pesquisa foi considerada de tipo aplicado, foi utilizada uma abordagem quantitativa de abrangência transversal e correlacional não-experimental. A técnica de pesquisa e o instrumento de questionário foram aplicados às variáveis do estudo em uma amostra de 59 empresários vinícolas, após a coleta dos dados, procedemos à tabulação e análise descritiva e inferencial, descobriu-se que a cultura fiscal está em um nível médio e a intenção de formalização está em um nível alto, realizando o teste Spearman's Rho obtivemos um significado de 0.165 o que indica que não há relação entre as variáveis, concluiu-se que não é necessário ter um alto índice de cultura fiscal para que o empresário tenha a intenção de formalizar, pois há empresários que têm uma cultura fiscal baixa e têm a intenção de formalizar, ao contrário de outros empresários que têm um alto nível de cultura fiscal e não têm a intenção de formalizar por falta de confiança no Estado, o que significa que cada variável tem direções independentes.

Palavras-chave: Fiscalidade, cultura fiscal, formalização, informalidade.

\section{INTRODUCCIÓN}

La importancia de la cultura tributaria está en cada persona, cada uno desarrolla el sitio que desea ocupar en la población, aumentando el sentido de responsabilidad y solidaridad. Esto quiere decir que las obligaciones tributarias benefician a la sociedad y al Estado que se encarga de cumplir con los objetivos (Sarduy \& Gancedo, 2016).

La tributación es muy importante para el crecimiento de un país, asegura el crecimiento económico y social para el desarrollo de la población. Los impuestos son uno de los principales métodos de ingreso público. Es por esto que el Estado tiene que ser más flexible en sus métodos y estrategias de recaudación, de esa manera fidelizar al contribuyente para su correcto cumplimiento de sus impuestos (Mejía et al., 2019).

Es importante tener la intensión de formalización para todo emprendedor que desee mantener y desarrollar su negocio de manera rentable (Thapa et al., 2021), la informalidad genera una competencia desleal entre emprendedores, así como también genera obstáculos para obtener un crédito financiero ya que es mucho más fácil si están formalizados (Giacomo et al., 2018), la importancia de la formalidad se debe considerar sobre los beneficios que conlleva la formalización, ya que la formalidad brinda ventajas a los emprendedores, como mayor rentabilidad, accesos a créditos financieros y mayor confiabilidad con los proveedores (Thanh, L. 2021).

En algunos países de América del Sur se evidenció un alto índice de falta de presencia gubernamental, por culpa de los diferentes niveles de gobierno, quienes son los únicos beneficiados con la recaudación de los tributos. Existen nuevas propuestas para la recaudación, donde el emprendedor no está de acuerdo ya que el único beneficiado es el Estado y no la sociedad. Por ejemplo, el nivel de evasión fiscal y tributaria en Venezuela desde hace años se presenta elevado, ya que los emprendedores no tienen bien definido las normas tributarias por que el Estado no viene distribuyendo de forma correcta las recaudaciones tributarias, creando desconfianza en los emprendedores (Morales et al., 2015).

Existen negocios informales que vienen ocasionando pérdidas económicas e impidiendo el crecimiento del país, complicando al Estado en cumplir sus metas de recaudación tributaria, concluyen señalando como factor principal la falta de cultura y educación tributaria, otro factor es la falta de interés de la Superintendencia Nacional De Aduanas y Administración Tributaria (SUNAT), ya que no orientan ni capacitan las normas y leyes tributarias a la población (Quispe, 2019). 
Convencer al emprendedor de formalizar y cumplir con sus obligaciones tributarias no es una tarea fácil para las entidades gubernamental, ya que esta actitud conlleva al aumento de evasiones tributarias (Vehovar et al., 2018), una encuesta realizada en México a microempresarios demuestra que el $75 \%$ de estos son informales, justificando su informalidad por el pequeño negocio que tienen, deduciendo que es la decisión más adecuada para ellos (Nohoua, 2021), para mejorar la formalización tributaria, las entidades gubernamentales deberían ser más transparentes para que los emprendedores estén más informados de la recaudación y beneficios que tendrán al pagar sus impuestos (Cristea et al., 2021).

El Estado peruano planteo regímenes tributarios con modificaciones que benefician a los emprendedores y a pesar de ello sigue existiendo la informalidad en los negocios, algunos si están registrados, pero evaden sus impuestos ya sea por falta de conocimiento o por beneficios personales, afectando al desarrollo del país (Chacaliaza, 2020).

La disposición y conducta que muestran los pobladores de la ciudad de Tarapoto, provincia y Departamento de San Martín, es la poca cultura tributaria en los pagos de sus obligaciones de impuestos, de esta manera se determina que el incumplimiento y la baja cultura tributaria, el motivo de los pobladores para no cumplir con sus obligaciones, es que la municipalidad y el Estado, realizan un mal uso de las contribuciones recaudadas (Iglesias et al, 2017).

Los emprendedores bodegueros en el distrito de Morales y región San Martín, vienen incrementando a raíz de esta pandemia ya que estos negocios venden productos de primera necesidad y es uno de los rubros que podían atender las 24 horas según disposición del Estado, la mayoría de estas bodegas empezaron sus actividades por necesidad de mercado y tienen intenciones de formalizarse en algún momento ya que por ahora están en la informalidad y no saben las consecuencias que este acto de evasión podría causarles.

Un factor principal es la falta de presencia de las entidades gubernamentales, no capacitan ni llegan a la población al cien por ciento, no fomentan la cultura tributaria, ni se enfocan en la problemática de las consecuencias que viene ocasionando el no cumplir con las obligaciones tributarias (Huari, 2016). Así mismo, se viene observando en el distrito de Morales que no hay presencia gubernamental para dar a conocer a los pequeños emprendedores de las consecuencias que podría llevarle.

Si no se fomenta la educación tributaria trae como consecuencia principal el incumplimiento y el no desarrollo de un país, al nivel de Latinoamérica la evasión tributaria es uno de los componentes para el poco desarrollo del país, el desinterés que muestran los ciudadanos por el cumplimiento de sus obligaciones viene afectando a la localidad (Huanca, 2017).

La principal consecuencia de la informalidad tributaria es la deficiencia de recaudación de ingresos, por no tener un sistema adecuado (Atuguba, 2021), como en la mayoría de los países latinoamericanos la preocupación de la informalidad ha ido creciendo, ya que los emprendedores se muestran con falta de interés, rechazo y evasión a la formalización (Carolina, 2008), para una recaudación exitosa es necesario capacitaciones constantes a los emprendedores, leyes accesibles, visitar al contribuyente ( Güneş, 2019).

El incumplimiento tributario trae como consecuencia principal el poco desarrollo de un país, no logra cumplir con sus metas trazadas para combatir la pobreza extrema, minimizar el hambre, contar con buenos equipos escolares, educación de calidad, contar con infraestructuras modernas de colegios y hospitales, que son las principales fuentes para el progreso del país (Flores et al., 2019).

El tema de investigación es cultura tributaria e intención de formalización de los emprendedores bodegueros del distrito de Morales de la región San Martín en el 2021. Para estudiar el nivel de cultura tributaria, según el autor Mejía et al. (2019), debe existir en los empresarios una conexión entre las normas gubernamentales y la cultura tributaria, ya que se determina en dos aspectos importantes: en los valores tributarios y en la percepción de los empresarios acerca del beneficio que el Estado brinda a la sociedad, ambas se relacionan entre sí. La cultura tributaria fue 
estudiada considerando los aportes de Casana (2019) y Neira (2019), la intención de formalización fue estudiada en base a los aportes de Calua et al. (2019) y Apaza (2018)

Según la investigación se realizó la pregunta general: ¿cuál es la relación entre la cultura tributaria y la intención de formalización de los emprendedores bodegueros del distrito de Morales de la región San Martín en el 2021?, de la misma forma se formuló las siguientes preguntas específicas: ¿cuál es el nivel de cultura tributaria de los emprendedores bodegueros del distrito de Morales de la región San Martín en el 2021?, ¿cuál es el nivel de intención de formalización de los emprendedores bodegueros del distrito de Morales de la región San Martín en el 2021?, ¿cuál es la relación de las dimensiones de la cultura tributaria con la intención de formalización?

La investigación se justificó por su relevancia social por el valor cultural tributario que debería tener cada empresario, para cumplir con sus obligaciones de manera voluntaria, responsable y honesto, de esa manera el empresario está informado sobre la cultura tributaria y podrá contribuir con el país, formalizarse y seguir cumpliendo con el crecimiento de sus negocios, también se justificó de manera práctica porque se incentivará a la concientización tributaria para los emprendedores.

En el objetivo general presentado se determinó la relación entre la cultura tributaria y la intención de formalización de los emprendedores bodegueros del distrito de Morales de la región San Martín en el 2021; de la misma forma se formuló los siguientes objetivos específicos: identificar el nivel de cultura tributaria de los emprendedores bodegueros del distrito de Morales de la región San Martín en el 2021, identificar el nivel de intención de formalización de los emprendedores bodegueros del distrito de Morales de la región San Martín en el 2021, determinar la relación de las dimensiones de la cultura tributaria con la intención de formalización de los emprendedores del distrito de Morales de la región San Martín en el 2021.

En la investigación se presentó como hipótesis general: la relación entre la cultura tributaria y la intención de formalización es significativa para los emprendedores bodegueros del distrito de Morales de la región San Martín en el año 2021.

\section{FUNDAMENTO TEÓRICO}

Burgos (2020) en su investigación realizado en Ecuador - Jipijapa, teniendo como objetivo principal relacionar la educación tributaria y el correcto cumplimiento tributario con los emprendedores rurales de la ciudad de Jipijapa. Se realizó un estudio descriptivo no experimental y estudio exploratorio, se aplicó la técnica de la encuesta, la muestra 127 negocios pequeños. Se concluyó que el $77,17 \%$ no conocen sobre la educación tributaria y que no están registrados en ninguna entidad gubernamental, el 22,83\%. El factor principal para que se puedan formalizar, es la falta de capacitaciones de las entidades gubernamentales.

Rivera et al, (2016) en su investigación realizado en México, planteó como objetivo principal analizar las normas implementadas en México para fomentar la legalidad de las pequeñas empresas en el sector rural y los incentivos para su formalización, el método que se aplicó es documental y de campo, dirigido a los emprendedores para verificar la facilidad que tienen para formalizarse, también se realizó entrevistas con especialistas en temas tributarios, la muestra que se utilizó son los pequeños negocios informales. Obteniendo como conclusión que la documentación y el proceso para la formalización son muy burocráticos.

Pastrana, (2020) está investigación fue realizada en Tacna - Perú, teniendo como principal objetivo identificar la relación entre la educación tributaria en la formalización de las MYPES, se utilizó un enfoque cuantitativo, tipo de estudio no experimental, diseño no experimental, con una población de 13 emprendedores textiles, la técnica utilizada fue la encuesta y el cuestionario como instrumento , la validación del instrumento se dio por el juicio de expertos, los resultados indicaron 
que un 53\% no son conscientes de cumplir con sus obligaciones del pago de sus tributos, llegando a la conclusión que gran parte de estos emprendedores carecen de conciencia tributaria y apoyo del Estado quien no orienta ni les brinda apoyo.

Brown, (2019) la investigación fue realizada en Perú, teniendo como principal objetivo determinar la manera en que la educación tributaria se relaciona con la informalidad en las MYPEs del sector comercial limeño, la investigación es de enfoque cuantitativo, tipo observacional, nivel correlacional es descriptivo, método general hipotético deductivo, con el diseño no experimental, el objeto de estudio la población bodegas, una muestra de 154 bodegas a quienes se aplicó sendas encuestas validadas y confiables, dando como resultados que existe un gran porcentaje de poca cultura tributaria en los emprendedores, se concluyó que la relación que existe entre las dos variables es alto, generando un alto índice de emprendedores informales.

Casique et al, (2019) en su investigación realizada en Tarapoto - Perú, tuvo como objetivo principal indicar la relación que tiene la falta de formalidad y el incumplimiento tributario de los emprendedores bodegueros del distrito de Tarapoto, Tipo de investigación aplicada, con diseño no experimental, se utilizó una muestra de 98 bodegas, la técnica utilizada fue la encuesta, instrumento el cuestionario, obteniendo como resultados que los emprendedores se mantienen en la informalidad para obtener mayor rentabilidad. Se concluyo que existe un nivel de $51 \%$ de informalidad en el distrito de Tarapoto, por ende, los emprendedores bodegueros tienen un índice muy bajo de cultura tributaria.

En las dimensiones de cultura tributaria, se consideró a Ortega (2019) quien indica las siguientes dimensiones: conocimiento, el nivel que tiene cada persona de la sociedad acerca de las obligaciones tributarias y las funciones que realiza; valores, determina la conducta de cada emprendedor en el presente o futuro, solo los emprendedores libres e informados son emprendedores honestos; actitudes, la actitud es el comportamiento de cada emprendedor, esta es quien decide lo positivo o negativo ante situaciones de decisión.

En las dimensiones de cultura tributaria, se consideró a Casana (2019) quien indica las siguientes dimensiones: normatividad, es el conocimiento que con lleva cada emprendedor acerca de los regímenes y obligaciones tributarias; actitud, el comportamiento y ganas de participar en capacitaciones o charlas tributarias.

La definición de formalidad según Ortega (2019) indica que es cumplir las normas que la ley exige, de esa manera la actividad económica es formal y legal pudiendo acceder a los beneficios que esta misma brinda. Según Batista (2020) define la formalidad como el cumplimiento de las obligaciones y los derechos que esto conlleva, así mismo es el cumplimiento de pago de impuestos para el crecimiento del país. COMPES (2019) define como un proceso amplio e importante para el desarrollo macroeconómico del país y de los emprendedores. La definición de intención según RAE "es la determinación de la voluntad en orden a un fin", considerando esta definición, se conceptualizó a la intención de la formalización como la voluntad de cada emprendedor a formalizar su negocio y cumplir con sus obligaciones tributarias y de esa manera obtener los beneficios gubernamentales.

En las dimensiones de intención de formalización: Inscripción para la legalización, el emprendedor debe tener en cuenta el registro de su negocio para que este sea legal ante el Estado; trámites para el funcionamiento, El proceso de requisitos y tramites que necesita cumplir el emprendedor para obtener su licencia de funcionamiento en su bodega.

\section{PROCEDIMIENTOS METODOLOGICOS}

\section{Tipo de investigación}


Según los aportes de CONCYTEC (2018), la investigación es de tipo aplicada, se utilizó un enfoque cuantitativo de tipo del estudio es no experimental, nos permite argumentar con aportes y establecer las dimensiones e indicadores registrados, logrando así reconocer el compartiendo de las variables.

\section{Diseño de investigación}

El diseño es no experimental, enfoque cuantitativo de tipo transversal y de alcance correlacional. Se tuvo que establecer como se relaciona la cultura tributaria en la intención de formalización de los emprendedores bodegueros del distrito de Morales - San Martín 2021.

\section{Variable 1: Cultura Tributaria}

En la investigación la cultura tributaria es importante para los nuevos emprendedores que deseen formalizar sus empresas, ya que de esta manera el emprendedor conoce sus beneficios y a donde está destinado sus aportes económicos que hace ante la entidad recaudadora (Yaguache et al, 2018).

\section{Variable 2: Formalización}

La intención de la formalización es la voluntad de cada emprendedor a formalizar su negocio y cumplir con sus obligaciones tributarias y de esa manera obtener los benéficos gubernamentales.

\section{Población:}

Está conformado por 59 emprendedores bodegueros del distrito de Morales - San Martín en el año 2021.

\section{- Criterios de inclusión:}

Se está considerando los emprendedores bodegueros informales del distrito del Morales San Martín en el año 2021.

\section{- Criterios de exclusión:}

Se considera como emprendedores bodegueros excluidos a los que no quisieron participar en la encuesta.

\section{Muestra:}

Se consideró como muestra los 59 emprendedores bodegueros del distrito de Morales - San Martín en el año 2021.

\section{Unidad de análisis:}


Emprendedores bodegueros del distrito de Morales - San Martín en el año 2021.

\section{Técnicas de recolección de datos}

Para las variables se consideró aplicar la técnica de la encuesta, el cual se aplicará a los emprendedores bodegueros del distrito de Morales - San Martín 2021.

\section{Instrumentos de recolección de datos}

El instrumento utilizado para la recolección de datos para las dos variables es el cuestionario, el cual fueron validados por juicio de expertos durante el desarrollo de la investigación, así también se analizó la información con una muestra piloto del programa estadístico SPSS, de las cuales se obtuvo el análisis de confiabilidad.

La validación de esta investigación fue validada por 3 expertos con mucha experiencia en temas de investigación.

\section{Procedimentos}

Para el primer y segundo objetivo, se procedió a utilizar el instrumento de encuesta de forma presencial a los emprendedores bodegueros informales del distrito de Morales, con los datos obtenidos se realizó un análisis descriptivo.

Para determinar el tercer y cuarto objetivo, se analizó las respuestas de los emprendedores y se procedió a tabular y obtener las estadísticas y poder determinar la relación que tiene la cultura tributaria y la intención de formalización de los emprendedores bodegueros.

\section{Método de análisis de datos}

Se empleó la estadística descriptiva, para determinar el nivel en cada variable con la información obtenida de todos los resultados de la encuesta, se procedió a realizar la tabulación la información en un software Excel, para luego proceder a mostrar los resultados en una tabla de frecuencia.

Se procedió a utilizar la estadística inferencial, como primer paso se realizó la prueba de normalidad de Kolmogorov Smirnov, ya que la muestra es más de 59 emprendedores, con los resultados obtenidos se aplicó la prueba de correlación de spearman de acuerdo a los resultados de la prueba de normalidad y de esta manera encontrar la relación que entre las variables y sus dimensiones.

\section{RESULTADOS Y DISCUSIÓN}

Objetivo Especifico 1: Identificar el nivel de cultura tributaria de los emprendedores bodegueros del distrito de Morales - San Martín 2021 
Tabla 1

Cultura tributaria de los emprendedores bodegueros 2021

\begin{tabular}{ccccc}
\hline \multirow{2}{*}{ Variable/Dimensión } & Nivel & Puntaje & $\begin{array}{c}\text { Cantidad de } \\
\text { bodegueros }\end{array}$ & Porcentaje \\
\hline \multirow{2}{*}{ Cultura tributaria } & Alto & 9 a 12 & 21 & $36 \%$ \\
& Medio & 5 a 8 & 33 & $56 \%$ \\
& Bajo & 0 a 4 & 14 & $8 \%$ \\
\hline \multirow{2}{*}{ Normatividad } & Alto & 5 a 6 & 11 & $24 \%$ \\
& Medio & 3 a 4 & 34 & $58 \%$ \\
& Bajo & 0 a 2 & 53 & $90 \%$ \\
Actitud & Alto & 5 a 6 & 2 & $3 \%$ \\
& Medio & 3 a 4 & 4 & $7 \%$
\end{tabular}

\section{Interpretación}

Según lo verificado, el nivel de cultura tributaria de los emprendedores bodegueros tiene un nivel medio del 56\%, así mismo solo el 36\% tienen un nivel alto y el $8 \%$ tiene un nivel bajo. En la dimensión de normatividad los emprendedores bodegueros tienen un nivel bajo del 58\%, solo el $24 \%$ tienen un nivel alto y un nivel medio el $18 \%$. En la dimensión de actitud verificamos que el $90 \%$ está en un nivel alto, en un nivel bajo el $7 \%$ y el $3 \%$ en un nivel medio.

El nivel de cultura tributaria de los emprendedores bodegueros encuestados del distrito de morales se encuentra en un nivel medio, la mayoría de los emprendedores tienen un poco de conocimiento que fue adquirido en distintas formas, ya sea en medios publicitarios o empíricamente, teniendo así el nivel de conocimiento normativo bajo, ya que el conocimiento que adquirieron fue en experiencias y hechos de su vida cotidiana, la mayoría de los emprendedores tiene la actitud en nivel alto de querer adquirir más conocimientos participando en charlas y capacitaciones para así formalizar su negocio.

Objetivo Especifico 2: Identificar el nivel de intención de formalización de los emprendedores bodegueros del distrito de Morales - San Martín 2021.

\section{Tabla 2}

Intención de formalización de los emprendedores bodegueros 2021

\begin{tabular}{lcccc}
\hline \multirow{2}{*}{ Variable/Dimensión } & Nivel & Puntaje & $\begin{array}{c}\text { Cantidad de } \\
\text { bodegueros }\end{array}$ & Porcentaje \\
\hline \multirow{2}{*}{ Intención de formalización } & Alto & 8 a 10 & 42 & $71 \%$ \\
& Medio & 4 a 7 & 6 & $10 \%$
\end{tabular}




\begin{tabular}{ccccc} 
& Bajo & 0 a 3 & 11 & $19 \%$ \\
\hline \multirow{2}{*}{$\begin{array}{c}\text { Inscripción para legalización } \\
\end{array}$} & Alto & 4 & 47 & $80 \%$ \\
& Medio & 3 & 0 & $0 \%$ \\
& Bajo & 0 a 2 & 12 & $20 \%$ \\
\hline $\begin{array}{c}\text { trámites para el } \\
\text { funcionamiento }\end{array}$ & Alto & 5 a 6 & 42 & $71 \%$ \\
& Medio & 3 a 4 & 15 & $25 \%$ \\
\hline
\end{tabular}

\section{Interpretación}

El nivel de intensión de formalización es alto con un $71 \%$, así mismo con un nivel bajo del $19 \%$ y el nivel medio del 10\%. En la dimensión de inscripción de legalización está en un nivel alto del $80 \%$ y nivel bajo con $20 \%$. En la dimensión de trámites para el funcionamiento contamos con un nivel alto del $71 \%$, un nivel bajo del $25 \%$ y un nivel medio del $4 \%$.

Los emprendedores bodegueros encuestados del distrito de morales la mayoría tienen la intención de formalizar su bodega, registrándose ante la SUNAT y cumpliendo con los requisitos establecidos para su formalización, así mismo están dispuestos a realizar los trámites para su licencia de funcionamiento y poder trabajar de forma legal para poder hacer crecer su negocio.

Objetivo Especifico 3: Determinar la relación de las dimensiones de la cultura tributaria con la intención de formalización de los emprendedores del distrito de Morales - San Martín 2021

\section{Tabla 3}

Análisis de correlación entre las dimensiones de la cultura tributaria con la intención de formalización

Prueba Dimensión $\quad \begin{aligned} & \text { Coeficiente de } \\ & \text { correlación }\end{aligned} \quad$ Significancia

$\begin{array}{llc} & \begin{array}{l}\text { Normatividad / Intención de } \\ \text { formalización }\end{array} & 0,179 \\ \text { Rho de Spearman } & & 0.176\end{array}$

\section{Interpretación}


Realizando la prueba de Sperman para identificar si existe correlación de las dimensiones de cultura tributaria entre la variable Intención de formalización, no existe correlación en ninguna de las dimensiones ambas van en direcciones diferentes, ya que para que existe correlación los porcentajes de significancia deberían ser menor o igual al 0.05

Objetivo General: Determinar la relación entre la cultura tributaria y la intención de formalización de los emprendedores bodegueros del distrito de Morales - San Martín 2021

\section{Tabla 4}

Análisis correlacional de las variables

$\begin{array}{llll}\text { Correlación } & \text { Variables } & \text { Coeficiente } & \text { Significancia }\end{array}$

\section{Cultura Tributaria}

$\begin{array}{llll}\text { Rho de Spearman } & \begin{array}{l}\text { Intención de } \\ \text { formalización }\end{array} & 0.183 & 0.165\end{array}$

\section{Interpretación}

Utilizando el software spss para el análisis correlacional de las variables, el spss nos muestra el resultado que nuestra variable independiente y la variable dependiente no existe relación entre ambas, ya que el resultado excede el porcentaje máximo que es el 0.05 para encontrar la relación entre las variables.

\section{Tabla 5}

Análisis del nivel de cultura tributaria y nivel de intensión de formalización

\begin{tabular}{|c|c|c|c|c|c|c|c|c|}
\hline \multirow{3}{*}{$\begin{array}{l}\text { Nivel de } \\
\text { cultura } \\
\text { tributaria }\end{array}$} & \multicolumn{6}{|c|}{ Nivel de intención de formalización } & \multirow{2}{*}{\multicolumn{2}{|c|}{ Total }} \\
\hline & \multicolumn{2}{|c|}{ Alto } & \multicolumn{2}{|c|}{ Medio } & \multicolumn{2}{|c|}{ Bajo } & & \\
\hline & ni & $\%$ & ni & $\%$ & ni & $\%$ & ni & $\%$ \\
\hline Alto & 15 & $25 \%$ & 4 & $7 \%$ & 2 & $3 \%$ & 21 & $36 \%$ \\
\hline Medio & 25 & $42 \%$ & 2 & $3 \%$ & 6 & $10 \%$ & 33 & $56 \%$ \\
\hline Bajo & 2 & $3 \%$ & 0 & $0 \%$ & 3 & $5 \%$ & 5 & $8 \%$ \\
\hline Total & 42 & $71 \%$ & 6 & $10 \%$ & 11 & $19 \%$ & 59 & $100 \%$ \\
\hline
\end{tabular}

ni $=$ número de individuos

\section{Interpretación}

La tabla 4 nos muestra que no existe relación entre nuestras variables, es por ello que realizamos la tabla 5 para detallar el comportamiento de estas; observando el grafico el mayor nivel de cultura tributaria es con un $56 \%$ en un nivel medio y el nivel de intención de formalización es 
alto con un 71\%; quiere decir que la mayoría de los emprendedores bodegueros del distrito de morales tienen un nivel de cultura tributaria medio y están dispuestas a formalizar su negocio, así como también existe emprendedores que tienen un nivel de cultura tributaria alto y no están dispuestos a formalizar; quiere decir que el nivel de cultura tributaria no define la intención de formalización.

\section{DISCUSIÓN}

Como primer objetivo específico de la investigación se consideró identificar el nivel de cultura tributaria de los emprendedores bodegueros del distrito de Morales, según los aportes de Sarduy y Gancedo (2016), la cultura tributaria es un conjunto de participaciones compartidas con el estado, que implica una labor educativa en la vida cotidiana de cada emprendedor y plantean que con una buena cultura tributaria se podrá mejorar el proceso de control y recaudación tributaria por parte de las entidades gubernamentales, eso garantizaría mejores recursos para el Estado y disminución de la evasión fiscal; en los resultados encontrados en la presente investigación se observó que el $56 \%$ de los emprendedores bodegueros tienen un nivel de cultura tributario medio, un $36 \%$ de los emprendedores bodegueros tienen un nivel de cultura tributaria alto y solo un $8 \%$ tienen poca cultura tributaria, así también, las dimensiones de normatividad tiene un nivel bajo con un 58\% y la dimensión de actitud tiene un nivel alto con un $90 \%$ siendo favorables. Estos resultados coinciden a los resultados encontrados por Casana (2019), quien en su investigación se encontró el nivel de cultura tributaria, el cual fue medido a través de las dimensiones de valores, normatividad y actitud, los resultados encontrados muestran que su nivel de cultura tributaria es de nivel medio con un 54.8\%. Estos resultados evidencian que el nivel de cultura tributaria de los emprendedores se encuentra en un nivel medio ya que obtuvieron el conocimiento a través de su vida cotidiana y mediante propagandas del Estado, recalcando que ambas investigaciones coinciden también en la dimensión de actitud ya que los emprendedores están dispuestos a obtener más conocimientos de la cultura tributaria.

Como segundo objetivo específico en la presente investigación, se consideró Identificar el nivel de intención de formalización de los emprendedores bodegueros del distrito de Morales, según los aportes de Thanh (2021), la formalización beneficia a ambas partes tanto para el emprendedor como el Estado, el Estado puede generar recursos con los impuestos recaudados y para los emprendedores se les abre varias ventajas como el acceso rápido a los créditos financieros y el respaldo de confiabilidad con sus proveedores, así mismo Thapa et al. (2021), indican que la formalización es una decisión ética y favorable para las empresas que quieran expandirse, fidelizar a sus clientes y gozar de los beneficios que pueden obtener siendo formales. En la presente investigación se encontró un resultado favorable, el nivel de intención de formalización de los emprendedores bodegueros del distrito de morales tiene un nivel alto con un $71 \%$, un nivel medio el $10 \%$ y un $19 \%$ el nivel bajo, la mayoría de los emprendedores encuestados tienen la intención de formalizar su bodega en cualquier momento. Estos resultados se asemejan a los resultados obtenidos por Rivera et al. (2016), teniendo como objetivo principal analizar las normas implementadas en México para fomentar la legalidad de las pequeñas empresas y los incentivos para su formalización, se encontró que los emprendedores tenían la intención de formalizar sus negocios, pero no había programas dirigidos a ellos para incentivar y mostrarles el proceso de formalización. Estos resultados evidencian que los emprendedores tienen la intención de formalización, pero por falta de incentivación y programas de apoyo no se logra con este objetivo.

Como tercer objetivo específico en la presente investigación, se consideró determinar la relación de las dimensiones de la cultura tributaria con la intención de formalización de los emprendedores del distrito de Morales, según el aporte de Nohoua (2021), indica que según los estudios que realizo el $70 \%$ de los emprendedores tienen la intención de formalizarse, pero parece no mostrase en la práctica ya que aún no se registran y es básicamente por la falta de presencia gubernamental. En la presente investigación se realizó la prueba de spearman para identificar el sí existe relación entre las dimensiones de cultura tributaria entre la variable intención de 
formalización donde se obtuvo que no existe relación con ninguna dimensión. Estos resultados obtenidos difieren a los obtenidos por Pastrana (2019), quien en su investigación busca identificar el nivel de influencia y la relación de cultura tributaria con la informalidad, el cual obtiene un resultado favorable e indican que existe relación entre sus variables. Estos resultados invitan a reflexionar, ya que la mayoría de los emprendedores tienen la actitud y la intención de formalizar aun no teniendo todos los conocimientos sobre cultura tributaria, y a los emprendedores que tienen y conocen bien la cultura tributaria y no tienen intención de formalizar les falta motivación y transparencia por parte de las entidades gubernamentales.

Como objetivo general se consideró determinar la relación entre la cultura tributaria y la intención de formalización de los emprendedores bodegueros del distrito de Morales, según el aporte de Burgos (2020) indica que la cultura tributaria es un indicador para la formalización de los emprendedores, así como también se debería crear entidades que motiven y orienten a los futuros contribuyentes, de esta manera incentivar al emprendedor a formalizarse y a cumplir con sus obligaciones tributarias sabiendo que está aportando al progreso de su país. En la presente investigación se realizó la prueba de Spearman para verificar si existe relación entre las variables de cultura tributaria e intención de formalización, el cual los resultados de la prueba Spearman no cumplen con el índice mínimo del 0.05 para que exista relación. Estos resultados coinciden con Brown (2019) quien indica que no existe relación de las variables entre la cultura tributaria y la informalidad. Estos resultados muestran que actualmente el nivel de cultura tributaria no define la intención de formalización, hay emprendedores que no tienen conocimiento de cultura tributaria y están dispuestos a formalizarse, así como también hay emprendedores que tienen cultura tributaria y no están dispuestos a formalizar por la poca fé y falta de transparencia que le tienen al Estado.

\section{CONCLUSIÓN}

De acuerdo al objetivo general: determinar la relación entre la cultura tributaria y la intención de formalización de los emprendedores bodegueros del distrito de Morales - San Martín 2021. se concluye que las variables cultura tributaria e intención de formalización no tienen relación alguna, ya que según el análisis realizado por Spearman se obtuvo una significancia de 0.165 no cumpliendo con el 0.05 para que se obtenga relación, esto representa que el emprendedor bodeguero no necesita tener un nivel alto de cultura tributaria para formalizar su negocio, como indica el resultado, el comportamiento de cada variable es independiente.

De acuerdo al primer objetivo específico: identificar el nivel de cultura tributaria de los emprendedores bodegueros del distrito de Morales - San Martín 2021. Se concluye que los emprendedores bodegueros del distrito de morales tienen un nivel de cultura tributaria medio alto que adquirieron de forma empírica con 56\%, su nivel de normatividad es bajo con un 58\% así mismo su nivel de actitud es alto con un $90 \%$, estos resultados indican que los emprendedores bodegueros del distrito de morales están dispuestos a participar en talleres que ofrezcan las entidades gubernamentales y así seguir adquiriendo conocimientos de cultura tributaria.

De acuerdo al segundo objetivo específico: identificar el nivel de intención de formalización de los emprendedores bodegueros del distrito de Morales - San Martín 2021. Se concluye que los emprendedores bodegueros del distrito de morales tienen un nivel de intención de formalización del $71 \%$ estando dispuesto a registrase ante SUNAT y realizar sus trámites de licencia de funcionamiento ante la municipalidad del distrito, la intención de formalización de estos emprendedores bodegueros es a un futuro ya que en la actualidad no lo creen conveniente por el pequeño tamaño de su negocio.

De acuerdo al tercer objetivo específico: determinar la relación de las dimensiones de la cultura tributaria con la intención de formalización de los emprendedores del distrito de Morales - 
San Martín 2021. Se concluye que no existe relación de las dimensiones de cultura tributaria con la variable intención de formalización ya que según el análisis realizado por Spearman se obtuvo una significancia de 0.176 y 0.752 no cumpliendo con el importe mínimo del 0.05 para obtener relación, estos resultados indican que las dimensiones con la variable intención de formalización son independientes.

Formular y Proponer nuevas estrategias de incentivo así mismo, mejorar la comunicación con las entidades gubernamentales y con el municipio para que los emprendedores socialicen y tengan más confianza de lo que se realiza con sus impuestos y tengan la intención de formalizar a fin de lograr una mejor cultura.

Elaborar un plan de concientización tributaria, basado en el rescate de valores, virtudes y cualidades de los emprendedores, para fortalecer lazos de confianza con el Estado y refleje reciprocidad del buen uso de los fondos recaudados para el bienestar y mejoramiento de la sociedad.

Invertir en talleres y capacitaciones disponibles para los emprendedores por parte de las entidades gubernamentales locales, de esa manera logrando concientizar y mejorar la relación de los emprendedores con las entidades, solo así se logrará inculcar a la formalización.

Se recomienda a los nuevos investigadores continuar con la investigación con una escala de medición tipo Likert, así mismo utilizar otros métodos de análisis para obtener resultados más precisos.

\section{REFERENCIAS}

Apaza, R. (2018). La cultura tributaria y la formalización de las empresas mineras en el Perú. Año 2018. Para optar el grado de Doctor en Contabilidad. Lima - Perú. Universidad Inca Garcilaso De La Vega. http://repositorio.uigv.edu.pe/handle/20.500.11818/2768

Atuguba, R. (2021). Tax Culture: Perspectives from an African State. American Journal of Trade and Policy, 8(1), 25-58. DOI: https://doi.org/10.18034/ajtp.v8i1.510

Batista, F. (2020). Formalidad Empresarial Un proceso multidimensional, no un estado binario. Cámara de Comercio de Santa Marta para el Magdalena, 1(1). file://C:/Users/abcde/Downloads/formalidad-empresarial_magdalena.pdf

Brown, R. (2020). La Cultura Tributaria Y La Informalidad En Las Mypes Del Sector Comercial De La Urbanización San Roque, Distrito De Santiago De Surco, 2019. Tesis para optar el Título Profesional de Contador Público. Carrera de Contabilidad. Lima - Perú: Universidad Nacional Federico Villareal. http://repositorio.unfv.edu.pe/handle/UNFV/4034

Burgos, M. (2020). La Cultura Tributaria De Los Pequeños Productores Rurales En La Feria Libre De Jipijapa. Colón Ciencias, Tecnología y Negocios. 7. 58-68. http://portal.amelica.org/ameli/jatsRepo/215/215974011/ index.htm

Calua, N.; García, N.; García, M. y Ruiz, L. (2016). Factores que desalientan la formalización de los empresarios de las micro y pequeñas empresas del sector de manufactura del rubro textil en el Emporio Comercial de Gamarra. Año 2016. Para optar el grado de licenciatura. Lima - Perú. Universidad Peruana De Ciencias Aplicadas. http://hdl.handle.net/10757/621084

Carolina, R. (2008). Estrategias para la formación de la cultura tributaria. Biblioteca asambleas generales. 42 - tema 1. https://www.ciat.org/Biblioteca/AsambleasGenerales/2008/Espanol/guatemala42_2008_tema1_Guatemala.pdf.

Casana, Y. (2019). Cultura tributaria y cumplimiento de obligaciones tributarias de comerciantes en un centro comercial trujillano. Para obtener el grado académico de bachiller en contabilidad. Trujillo - Perú. Universidad César Vallejo. https://hdl.handle.net/20.500.12692/53830

Casique, J.; Garate, LL.; Hidalgo, M. y Tapia, E. (2020). Informalidad y su relación con la evasión tributaria en las bodegas del distrito de Tarapoto 2019. Tesis para optar el Título Profesional de Contador Público. Carrera de Contabilidad. Tarapoto - Perú: Universidad César Vallejo. https://hdl.handle.net/20.500.12692/55122

CONPES 3956 (2019). Política De Formalización Empresarial. Revista de actualidad jurídica para la inclusión y el desarrollo social. 1(1). https://colaboracion.dnp.gov.co/CDT/Conpes/Econ\%C3\%B3micos/3956.pdf 
Cristea, A., Voda, A. y Ungureanu, D. (2021). Tax Culture: Approached As A New Constituent Element Of The Fiscal System. Annals - Economy Series, 2021, vol. 2, 124-132. https://www.utgjiu.ro/revista/ec/pdf/2021-02/15_Cristea.pdf

Chacaliaza, Ítalo. (2020). El régimen tributario en la formalización de las MYPES de Ica, 2016 - 2017. Consensus, 24(1), 27-36. https://doi.org/10.33539/consensus.2019.v24n1.2240

Emprendedor Sunat. (19 de Febrero de 2019). Obtenido de http://emprender.sunat.gob.pe/que-beneficios-tengo

Giacomo, G., Matthew, P,. y Aminur, R. (2018) La formalización de las pequeñas empresas: el tratamiento del palo, The Journal of Development Studies, 54: 6, 983-1001. DOI: 10.1080 / 00220388.2017.1327660

Güneş, Ç., Feride B. y Adnan, G. (2019) The importance of tax literacy in tax compliance, suggestions to be developed in the case of country applications. Interna $\square$ onal Public Finance Conference / Turkey. 24-27, 2019. 10.26650/PB/SS10.2019.001.032

Gutiérrez, C. (2017). Obligación tributaria e incidencia en la conformación de microempresas en el sur de la ciudad de Guayaquil. Espirales Revista Multidisciplinaria de investigación.1(8). https://doi.org/10.31876/re.v1i8.78

Huanca, D. (2017). La Política Tributaria Municipal y la Cultura Tributaria de los Contribuyentes de la Urbanización Magisterio del Distrito de Cusco, año 2017. Tesis para obtener el Grado Académico de Maestro en Gestión Pública. Cusco - Perú: Universidad César Vallejo. http://repositorio.ucv.edu.pe/handle/UCV/20159

Iglesias, J. y Ruiz, K. (2017). La cultura tributaria y su relación con las obligaciones tributarias de los arbitrios municipales de la ciudad de Tarapoto año 2016. Tesis para optar el Título Profesional de Contador Público. Carrera de Contabilidad. Tarapoto, Perú: Universidad Peruana Unión. http://repositorio.upeu.edu.pe/handle/UPEU/685

Mejía, O.; Pino, R. y Parrales, C. (2019). Políticas tributarias y la evasión fiscal en la República del Ecuador, Aproximación a un modelo teórico. Revista Venezolana de Gerencia, 24(88),1147-1165. https://www.redalyc.org/articulo.oa?id=29062051010

Neira, M. (2019). La cultura tributaria en la recaudación de los tributos. DOI: 10.23857/pc.v4i8.1055

Nohoua, T. (2021). Business Environment Effect on Formalization Willingness and Registration Decision of SMEs in Ivory Coast. The Journal of Applied Business and Economics, 23(5), 11-29. https://doi.org/10.33423/jabe.v23i5.4560

Ortega, I. (2019). La cultura tributaria y su incidencia en la formalización de las mypes de la provincia de San Pablo - Región Cajamarca. Año 2018. Para Optar El Grado Académico De Maestro En Ciencias. Cajamarca - Perú. Universidad Nacional De Cajamarca. http://repositorio.unc.edu.pe/handle/UNC/3268

Pastrana, J. (2020). Cultura Tributaria y La Formalización De Las Mypes Textiles Del Distrito De Huancavelica Periodo 2020. Tesis para optar el Título Profesional de Contador Público. Carrera de Contabilidad. Pimentel - Perú: Universidad Señor de Sipán. https://hdl.handle.net/20.500.12802/7740

Quispe, L. (2019). La evasión tributaria y su relación con la recaudación tributaria en los comerciantes del mercado Familias Unidas de San Juan Miraflores en el año 2018. Tesis para optar el Título Profesional de Contador Público. Carrera de Contabilidad. Lima, Perú: Universidad Autónoma del Perú. http://repositorio.autonoma.edu.pe/handle/AUTONOMA/868

Rivera, R.; López, N. y Mendoza, A. (2016). Políticas de apoyo a la productividad de la microempresa informal ¿dónde está México? Revista Latinoamericana de Economía, 47(184),87-109. https://www.redalyc.org/articulo.oa?id=11843154005

Sarduy, M. y Gancedo, I. (2016). La cultura tributaria en la sociedad cubana: un problema a resolver. Cofín Habana, 10(1), 113-125. http://scielo.sld.cu/scielo.php?script=sci_arttext\&pid=S207360612016000100010\&lng=es\&tlng=es

Segura, R. (2019). Cultura tributaria y su relación con la formalización de las mypes del sector abarrotes de la ciudad de Huánuco 2019. Para optar el título profesional de contador público. Huánuco - Perú. Universidad de Huánuco. http://repositorio.udh.edu.pe/123456789/1971

Thapa, S., Xheneti, M. y Madden, A. (2021). To Formalize or Not to Formalize: Women Entrepreneurs' Sensemaking of Business Registration in the Context of Nepal. J Bus Ethics. 173, 687-708. https://doi.org/10.1007/s10551-020-04541-1

Thanh, L. (2021) Formality and Financing Patterns of Small and Medium-Sized Enterprises in Vietnam, Emerging Markets Finance and Trade, 57:10, 2852-2869. DOI: 10.1080/1540496X.2019.1658576 
Vehovar, A., Mumel, D. y Hauptman, L. (2018). Un modelo conceptual de la relación entre los valores personales y la cultura tributaria personal en cuanto a la percepción de equidad del sistema tributario. Naše gospodarstvo / Nuestra economía, 64(1), 41-47. DOI: 10.2478 / ngoe-2018-0005

Yaguache, M., Pardo, M., y Espejo, L. (2018). Estrategias para fomentar la cultura tributaria desde la academia. Caso UTPL. Artículo de Investigación. Revista Killkana Sociales. Vol. 2, No. 3, pp. 145-152, DOI: https://doi.org/10.26871/killkana_social.v2i3.341 